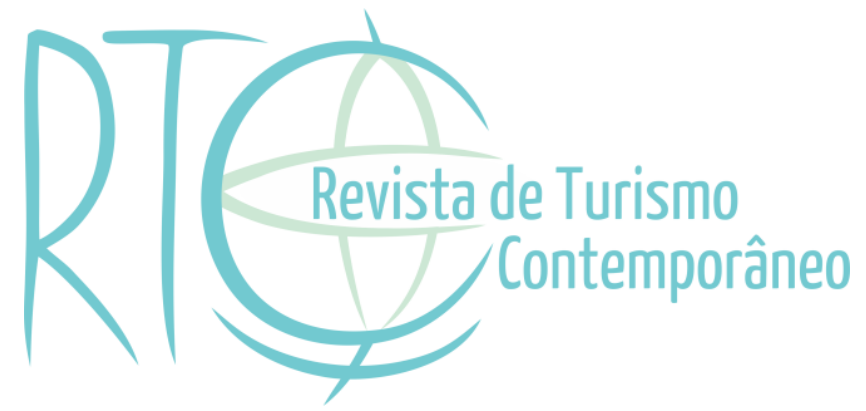

\title{
Turismo e o pós-evento olímpico: uma gestão mercadológica da cidade do Rio de Janeiro
}

Tourism and the post-Olympic event: a market management of the Rio de Janeiro city

\section{Roberto Paolo Vico}

Pesquisador no Grupo Interdisciplinar em Estudos do Lazer da Escola de Artes, Ciências e Humanidades da Universidade de São Paulo - USP, São Paulo/SP, Brasil

E-mail: roberto.paolo.vico@gmail.com

\section{Verónica Cecílio Chiundila}

Mestranda em Turismo pelo Programa de Pós-graduação em Turismo da Universidade Federal do Rio Grande do Norte - UFRN, Natal/RN, Brasil

E-mail: nicachiundila@gmail.com 


\section{RESUMO}

A organização de um grande evento como uma Olimpíada comporta consideráveis investimentos que devem ser realizados para responder às exigências do Comitê Olímpico Internacional e, na atual conjuntura global, numa perspectiva de competição internacional, os sistemas territoriais são sempre mais chamados a elevar as próprias dotações estruturais e infraestruturais. É neste cenário que esses eventos deveriam desenvolver um importante papel como catalisadores de transformações territoriais e sociais, mudanças que às vezes não acontecem ou impactam de maneira negativa a população local e o território. O presente artigo propõe a distância de alguns anos da realização da Olimpíada do Rio de Janeiro, uma síntese que sublinha as características e as problemáticas ligadas às heranças do megaevento, uma cidade influenciada pela crise econômica, política e social do Brasil nos últimos anos. Como resultados deste estudo evidenciam-se, em particular, diversos aspectos negativos relacionados a uma má gestão do megaevento e do seu legado como: as expropriações dos moradores, o enobrecimento de alguns bairros com o fenômeno da gentrification, a falência do sistema de segurança, o endividamento do Estado, a corrupção generalizada face aos elevados investimentos realizados bem como o abandono de muitas infraestruturas e instalações esportivas. Do ponto de vista metodológico, a análise apresentada baseou-se em uma abordagem qualitativa, fundamentalmente em revisão bibliográfica, utilização de matérias jornalísticas recentes e entrevistas com professores, pesquisadores e profissionais do setor. Utilizou-se como referencial teórico para a discussão autores como Ritchie, Hall, Chalkley e Essex, Gaffney, Rolnik e Fontaine.

Palavras-chave: Turismo. Evento. Olimpíadas. Rio de Janeiro.

\section{ABSTRACT}

The organization of a big event such as an Olympiad entails considerable investments that must be made to meet the requirements of the International Olympic Committee and, in the current global context, territories, from a perspective of international competition, are always called upon to raise their own structural systems and infrastructure. It is in this scenario that the Olympics should play an important role as catalysts of territorial and social transformations; changes that sometimes do not happen or negatively impact the local population and the territory. This article proposes, at a distance of a few years from the Rio de Janeiro Olympics, a synthesis that underlines the characteristics and problems associated with the legacies of the mega event, a city affected by the economic, political and social crisis of Brazil in recent years. The results of this study show, in particular, several negative aspects related to poor management of the mega-event and its legacy as: the expropriations of the residents, the ennoblement of some neighborhoods with the phenomenon of gentrification, the inefficiency of the security system, the indebtedness of the State of Rio de Janeiro, widespread corruption in view of high investments made, the abandonment of many infrastructures and sports facilities. From the methodological point of view, the analysis presented was based on a qualitative approach, fundamentally in a bibliographic review, use of recent journalistic material and interviews with professors, researchers and professionals of the sector. Authors such as Ritchie, Hall, Chalkley e Essex, Gaffney, Rolnik and Fontaine have been used as theoretical references.

Keywords: Tourism. Event. Olympics. Rio de Janeiro. 


\section{INTRODUÇÃO}

Na ótica do marketing territorial, os megaeventos esportivos, nomeadamente, os jogos olímpicos, são acontecimentos com a capacidade de melhorar ou relançar a imagem do território, atrair fluxos de capitais, valorizar os recursos e ativar processos de desenvolvimento. Neste contexto, o evento deve ser avaliado de acordo com as questões que nele impactam, pela sua simplicidade ou complexidade, pela dimensão do público-alvo, pela sua finalidade e forma de abrangência, assim como pela garantia de financiamento e capacidade técnica que o acarretam (Watt, 2004).

De fato, na maior parte dos casos, os megaeventos, nomeadamente, as olimpíadas comportam altos investimentos e um envolvimento importante do tecido urbano das cidades anfitriãs; por este motivo as problemáticas que caraterizam os megaeventos esportivos estão em estreita relação com os processos de transformação da cidade.

As recentes proliferações dessas ocasiões extraordinárias de transformação urbana, quais sejam os megaeventos, tornaram mais evidentes as questões da sustentabilidade do desenvolvimento. Embora estas ações sejam promovidas com o objetivo de melhoria da qualidade urbana e ambiental, bem como do desenvolvimento econômico e social, em muitos casos os resultados não se revelam como os que eram inicialmente desejados.

Frequentemente, as exigências de mercado ultrapassam os interesses locais e os objetivos da sustentabilidade territorial e social correm o perigo de ficar num simples pretexto hipotético: uma práxis sempre mais comum também no âmbito dos megaeventos, cuja importância no desenvolvimento das cidades incrementou de forma exponencial nos últimos trinta anos (Vico, 2016; Vico, Uvinha \& Gustavo, 2018).

As Olimpíadas, por sua vez, são consideradas na literatura acadêmica megaeventos por excelência; são reputadas também como as principais oportunidades para atrair investimentos, conceber obras públicas, iniciativas privadas relacionadas e uma maneira para apresentar mundialmente a cidade. Neste prisma, o artigo tem como foco de análise o fenômeno dos megaeventos esportivos, com ênfase nos Jogos Olímpicos do Rio de Janeiro de 2016, como instrumentos duvidosos para a criação de valor do território em termos de legados e de benefícios futuros ao longo prazo.

Assim, buscamos identificar e analisar aspectos relacionados às transformações socioterritoriais derivantes da organização dos Jogos Olímpicos do Rio de Janeiro de 2016. Ainda, iremos apresentar indicadores sócio-territoriais como proposição de políticas públicas para as cidades que recebem megaeventos esportivos. 
Do ponto de vista do referencial teórico, começou-se com a análise das definições e das diferentes tipologias de megaeventos mediante autores como Ritchie (1984), Hall (1997), Allen, O’Toole, McDonnel e Haris (2003) e Pedro, Caetano, Christiani e Rasquilha (2005). Seguiu-se com a análise de Chalkley e Essex que abordaram a questão da competitividade internacional entre as cidades para angariar o direito de poder tornar-se cidade-sede para sediar os Jogos Olímpicos, e de Gaffney que trata como os megaeventos esportivos mundiais, como as Olimpíadas do Rio de Janeiro de 2016, transformaram-se em um business model na era globalizada, responsáveis pela atração de fluxos financeiros, reestruturação de circuitos de circulação e acumulação local.

Ao que se refere ao caso de estudo dos Jogos Olímpicos de Rio de Janeiro, serviu-se das leituras e das informações de Rolnik e de Fontaine que salientaram a delicada questão dos efeitos sobre o território e a população que derivaram do uso do espaço e das transformações territoriais realizadas. Além disso, são apresentadas informações e dados examinando os investimentos realizados e alguns tipos de efeitos derivantes dos mesmos como as expropriações e remoções de moradores, o fenômeno da gentrificação e do enobrecimento de bairros depois da especulação imobiliária, o não aproveitamento das instalações esportivas e das habitações "olímpicas" e o endividamento do Estado.

\section{MEGAEVENTOS - DEFINIÇÕES E TIPOLOGIAS}

São os grandes eventos, capazes de atrair um enorme número de visitantes e uma elevada atenção por parte dos meios de comunicação de massa a nível internacional obtendo, consequentemente, um impacto fortíssimo em termos económicos e de notoriedade sobre as localidades anfitriãs. Em literatura, não existe nenhum acordo verdadeiro sobre a definição de grandes ou megaeventos, frequentemente os autores referem-se chamando-os também de hallmark ou special events. O conceito de megaevento foi introduzido por Ritchie (1984), segundo o qual trata-se de um evento importante, organizado uma ou mais vezes, de duração limitada, o qual serve para aumentar a consciência, a imagem e a economia de um destino turístico a curto e/ou longo prazo. O sucesso de tais eventos depende da sua unicidade, importância ou dimensão com o fim de criar interesse e suscitar atenção. Segundo Allen et al. (2003) e Pedro et al. (2005), os megaeventos afetam as economias internas e repercutem-se na mídia global, atraindo milhões de pessoas e multinacionais. Tratam-se de iniciativas de duração limitada no tempo, diversificadas por tipologia de oferta e serviços prestados, com um envolvimento massivo de pessoas. $\mathrm{Na}$ maioria dos casos, estes eventos comportam investimentos consideráveis e um envolvimento importante do tecido urbano das cidades que 
os acolhem; por este motivo as problemáticas que caráterizam os grandes eventos (ou megaeventos) estão em estreita relação com os processos de transformação das cidades. Pertencem à categoria dos megaeventos: as feiras, os festivais, as exposições, os acontecimentos desportivos e os acontecimentos culturais entre outros.

De acordo com os diferentes autores, existem diferentes definições de megaevento, porém no geral se podem inumerar algumas caraterísticas chave, tais como:

- O aumento da procura produzida pelo evento relaciona-se com uma série de serviços auxiliares (hotéis, restaurantes, sistemas de transporte, espetáculos, lazer, etc.) e não exclusivamente com o próprio evento;

- Tal procura concentra-se em um período relativamente breve;

- A proveniência dos financiamentos geralmente não é local.

Estas manifestações, embora sejam de duração limitada no tempo, têm implicações que vão além da temática específica do próprio evento e envolvem fatores de natureza socioeconómica e cultural com impactos a longo prazo e a nível continental, se não mundial.

Um evento pode definir-se "mega", não somente pelas suas dimensões ou pela quantidade de visitantes que consegue atrair, mas também considerando o efeito psicológico que tem na opinião pública, o que chama a atenção dos mass media e a sua conseguinte difusão internacional através da imprensa, rádio, televisão e internet. Geralmente são realizados em importantes localidades turísticas, (muitas vezes em grandes cidades), pela grande capacidade de receber pessoas e por consequente pelo valor atribuído ao evento. Para organizar um grande evento é necessário que o mesmo contribua para fomentar o interesse no setor dos transportes, do comércio e que tenha um impacto positivo nos consumos turísticos.

Até este ponto o problema é conseguir distinguir o grande evento de um evento comum (que é repetitivo e sem originalidade, logo de fraco interesse para a opinião pública), daí que muitos estudiosos consideram como discriminante a unicidade. Se um grande evento é único (ou seja, não repetível) e original, irá conseguir atrair a atenção para além das fronteiras do território ao qual se apresenta. Como já se viu, o evento em si não é um elemento inovador, porém as inovações foram introduzidas na organização, no financiamento dos mesmos e na maneirade reduzir o seu impacto económico, social e ambiental. Em suma, o lucro de um evento não pode ser medido unicamente através de uma análise financeira a curto prazo, pelo que será necessário considerar a capacidade de promover o lugar, a administração (que o geriu), a sociedade civil (que o sustentou) e a conseguinte imagem do lugar percebida 
de maneira positiva. Os megaeventos podem ser subdivididos em quatro categorias segundo a sua periodicidade, em particular:

Tabela 1 - Tipologias de megaeventos segundo a sua periodicidade

\begin{tabular}{|l|r|}
\hline \multicolumn{1}{|c|}{ Periodicidade } & Exemplo \\
\hline Eventos sazonais & Mostras de arte, feiras enogastronomicas e culturais etc.. \\
\hline Eventos anuais & Festivais, espetáculos, Grand Prix, Tour de France etc.. \\
\hline Eventos cíclicos & Mundiais de Futebol, Jogos Olímpicos, Expos, etc.. \\
\hline Eventos excecionais & $\begin{array}{r}\text { Celebrações de recorrências históricas, cerimonias funebres de } \\
\text { personagens ilustres etc.. }\end{array}$ \\
\hline
\end{tabular}

Fonte: Adaptado pelo autor com base em vários autores, 2018.

Até aqui evidenciaram-se as diferentes definições da literatura, sem chegar a uma classificação única. Com este trabalho pretende-se dar uma definição metodológica e de ampla aplicabilidade, classificando os megaeventos com base a três elementos:

1. A dimensão do evento, que tenha em conta de todos os fatores que fazem dele um megaevento (atores envolvidos, participação, cobertura mediática, orçamento, impactos territoriais);

2. A motivação do evento (negócios e comércio, religiosa, desportiva, etc.);

3. As caraterísticas intrínsecas do evento.

As motivações que induzem a organizar um evento podem ser as mais diversas. Neste contexto procurar-se-á dar uma visão completa sobre algumas tipologias de megaeventos, pelos quais, atualmente, as cidades competem. Quando se fala em megaeventos, são realizadas frequentemente referências aos Mundiais de Futebol (organizados pela FIFA), às Exposições Universais e Internacionais, aos Jogos Olímpicos de Verão e de Inverno, aos Jubileus (outros megaeventos religiosos), aos Grandes Prémios de Formula 1, aos Jogos Panamericanos, aos Jogos Asiáticos e Africanos, ao Tour de France, entre outros. Os megaeventos parecem ser domínio dos megaeventos esportivos; isto porque, tais eventos resultam ter os maiores impactos sobre os territórios anfitriões e os organizadores e/ou as comunidades locais esperam no pós-evento um grande número de legados ou heranças positivas. Daí que regra geral, não se citam megaeventos como as Capitais da Cultura, os Meetings dos G7/G8/G20, as Cimeiras Mundiais sobre o meio ambiente ou sobre outras temáticas de importância internacional. Os megaeventos tornaram-se de extraordinário interesse não só porque atraem turistas, mas também porque podem deixar heranças, que 
podem ter um impacto sobre as comunidades anfitriãs mais duradouro que a sua própria duração (Hall, 1997). Sempre Hall (1997) afirma que um megaevento atua como um catalisador da mudança, induzindo as pessoas a trabalhar juntas por um objetivo comum para obter financiamentos adicionais e ver realizados os projetos. Consequentemente e em concomitância desta atenção por parte da sociedade, também os estudiosos e os investigadores deram grande importância ao tema nas suas pesquisas. Interessa aqui sublinhar a grande atenção que os eventos, (mas, sobretudo os megaeventos), têm suscitado entre as elites das cidades e das nações de hoje em dia. Os megaeventos são vistos como uma enorme oportunidade para atrair recursos, investimentos e a atenção por parte do público (real/virtual ou nacional/internacional). As diferentes tipologias de megaeventos propostas anteriormente, além de restituir uma visão geral sobre o atual mercado dos eventos, também colocou em luz, as possibilidades que se oferecem aos territórios para que consigam competir numa escala global e as oportunidades nas diferentes formas e intensidades de incidir sobre o tecido urbano e territorial. Os vários eventos respondem às diferentes ambições e modalidades de organizar o território. Os megaeventos esportivos, como Mundiais de Futebol, Jogos Olímpicos, Jogos Asiáticos, Jogos Pan-americanos, entre outros, dão um destaque às instalações desportivas (novas ou a reabilitar). Todavia, como se viu especialmente para os Mundiais de Futebol e para as Olimpíadas, dado o número de participantes, outras intervenções de caráter territorial tornam-se necessárias para acolher, da melhor maneira, estas manifestações. Outros eventos esportivos, como os Grand Prix de Formula 1, que movimentam milhares de milhões de euros (graças aos patrocínios e às marcas automobilísticas), não são muito ligados a uma verdadeira competição, mas respondem principalmente a leis de mercado. Tais eventos de fato são organizados quando um território edifica uma pista de Formula 1 e consegue convencer todos os stakeholders a organizar um grande prémio. As vantagens destes eventos é que o território se dota destas estruturas o que lhe permitem acolher o dito evento, adquirindo uma vantagem competitiva não indiferente, pois o Grand Prix na maioria dos casos acontece anualmente. Os benefícios que derivam da repetição de forma cíclica origina a recuperação mais célere, dos custos associados à construção e manutenção. Os megaeventos culturais, como, por exemplo, as Capitais da Cultura ou os Fóruns Universais da Cultura, desejam, sobretudo, deixar no território, um legado de facilities culturais, tais como: centros-congressos, teatros, infraestruturas sociais e infraestruturas culturais. A finalidade à qual se responde é aquela de vitalizar os contextos de referência e permitir aos territórios que acolhem o evento, de propor-se a nível internacional com uma oferta cultural integrada, mesmo depois do fim do evento. Candidatar-se para um 
megaevento é muito dispendioso, pelo que os territórios interessados deveriam, antes de começar a trabalhar com qualquer evento, sondar os diferentes níveis organizativos e institucionais, ao fim de assegurarem o apoio político e financeiro para a organização do evento.

Tabela 2 - Requisitos necessários básicos para poder acolher um megaevento

\begin{tabular}{|c|c|}
\hline Megaevento & Requisitos \\
\hline $\begin{array}{l}\text { Mundiais de } \\
\text { Futebol }\end{array}$ & $\begin{array}{c}\text { Pelo menos } 12 \text { estádios, dos quais } 2 \text { com uma capacidade mínima de } 80.000 \\
\text { lugares; estruturas recetoras com padrões internacionais }\end{array}$ \\
\hline Jogos Olímpicos & $\begin{array}{l}\text { Vila Olímpica; mass media; estruturas esportivas multifuncionais com elevados } \\
\text { padrões de qualidade; estádio olímpico com mínimo } 100.000 \text { lugares; estruturas } \\
\text { recetoras com padrões internacionais }\end{array}$ \\
\hline $\begin{array}{l}\text { Expo(s) mundiais } \\
\text { e universais }\end{array}$ & $\begin{array}{c}\text { Pavilhões expositivos; estandes; estruturas recetoras com padrões } \\
\text { internacionais; serviços auxiliares }\end{array}$ \\
\hline $\begin{array}{l}\text { Grand Prix de } \\
\text { Formula } 1\end{array}$ & Circuito de Formula 1 e serviços auxiliares \\
\hline Capital da cultura & $\begin{array}{l}\text { Estruturas culturais (teatros, cinemas, centros para congressos etc.); } \\
\text { restruturação da cidade }\end{array}$ \\
\hline $\begin{array}{l}\text { Fórum universal } \\
\text { da cultura }\end{array}$ & Estruturas para congressos; regeneração urbana e dos espaços públicos \\
\hline Jogos mundiais & Estruturas esportivas multifuncionais com padrões internacionais; \\
\hline $\begin{array}{l}\text { Jogos Pan- } \\
\text { americanos / } \\
\text { Asiáticos / } \\
\text { Africanos }\end{array}$ & Estruturas esportivas multifuncionais e requalificação urbana \\
\hline
\end{tabular}

Fonte: Elaborado pelo autor com base em várias fontes, 2018.

Pela tabela anterior é possível obter um primeiro confronto dos requisitos necessários por alguns megaeventos. Conhecendo já as caraterísticas dos megaeventos, as qualidades dos territórios (em termos de obstáculos e limites, mas também de oportunidades e pontos de força) deveria ter-se em alta consideração quando começa-se a refletir sobre a possibilidade de organizar um megaevento.

Cada megaevento tem em si um caráter com o qual os territórios devem confrontar-se. Nem todos os territórios podem ter a ambição de acolher e organizar todos os megaeventos e nem todos os megaeventos, podem adaptar-se a ser acolhidos em qualquer território. 


\section{A COMPETIÇÃO ENTRE AS CIDADES}

A reestruturação hodierna do capitalismo influenciou profundamente a maneira de produzir, gerir e administrar as cidades. Assim como salienta Mascarenhas (2016, p. 16), a nível global, "elas passaram a assumir um novo protagonismo obcecado pela competição interurbana (...), através da ascensão de políticas neoliberais que acentuam a preocupante desigualdade socioespacial”.

A partir do início dos anos 1990 assistiu-se a uma mudança da forma de reprodução do capital nas economias urbanas, em particular na maneira como as cidades são gerenciadas. As cidades transformaram-se em locais de produção, consumo, inovação e de novos estilos de vida, assumindo-se como lugares de gestão da produção. As cidades são obrigadas a competir para atrair os consumidores e investidores sendo que os investimentos externos estão mais relacionados com a imagem que uma cidade sabe comunicar (Whitson \& Horne, 2006). Os processos estão em rápida evolução a par das dinâmicas e tendências de um modelo neoliberal global. Os megaeventos, nesta ótica, são utilizados, sobretudo, como aceleradores dos processos de consenso e de revitalização do território ao fim de se dotarem de estruturas e infraestruturas necessárias à competição internacional (Essex \& Chalckley, 1998). Nesse sentido, os megaeventos globais tornam-se instrumentos próprios do marketing territorial de uma cidade, região ou nação. Mas se se considera o território como centro da competitividade internacional das empresas (que ali residem e operam), quem compete nas diferentes escalas não são os territórios, mas sim as empresas. As cidades agora gestadas como empresas oferecem ao capital internacional novas possibilidades de negócios e tais negócios se realizam através dos megaeventos. O espaço de competência configurar-se-ia, como uma série de vínculos e de oportunidades ligados às peculiaridades intrínsecas do mesmo, à conformação física, à dotação da infraestrutura, mas também à conjuntura política e administrativa, aos níveis colaborativos e de eficiência.

Resumindo, as cidades contemporâneas são chamadas a responder às diferentes necessidades que provêm dos diferentes agentes que vivem, utilizam e consomem nas cidades. As cidades têm a necessidade de competirem sobre diversas escalas, (regional, nacional, internacional e global). Com o intuito de satisfazer as necessidades dos sujeitos envolvidos, as cidades precisam se regenerar, encontrando novas soluções urbanas para vencer os desafios futuros. Tornam-se ponto estratégico, os conceitos como a acessibilidade, a sustentabilidade, a eficiência e a inovação. Um grande número de cidadãos e trabalhadores decide viver na cidade pela qualidade e a quantidade de serviços oferecidos, pela 
possibilidade de encontrar formas de diversão e lazer, pela capacidade inovadora em vários setores, no entanto, existem cidades que melhor satisfazem e sabem satisfazer tais exigências e essas são as mais competitivas.

Por outro lado, os megaeventos podem ser um recurso à disposição das cidades e dos territórios a fim de alcançar muitos dos objetivos que as administrações locais desejam com o tão esperado legado, tais como: o aumento dos padrões qualitativos e ambientais, a ampliação das infraestruturas territoriais, o crescimento da notoriedade, o nível de atratividade do destino, a cidade como destino turístico e lugar ideal para a aplicação de investimentos estrangeiros. Enfim, espera-se que os megaeventos sejam uma janela de oportunidades para as cidades que os recebem.

Chalkley e Essex (1999) evidenciam o valor dos megaeventos esportivos como estímulo para importantes desenvolvimentos. Tais desenvolvimentos, além de ser necessários para vencer e para poder acolher megaeventos, servem também para melhorar os pressupostos, as condições e as oportunidades da competitividade das empresas locais atraindo novas empresas, devido a melhores condições gerais do contexto. As cidades podem oferecer vantagens competitivas visando acolher os megaeventos, pois estes permitem ter uma enorme visibilidade ao nível global. Através desta oportunidade de marketing territorial, as cidades podem transmitir os próprios valores, podendo comunicar os próprios recursos em termos ambientais, culturais e urbanísticos. A competição entre cidades desenvolve-se também com o atrair não somente capitais financeiros, mas também e, sobretudo capital humano e know how. Esta tipologia de capital humano, formada por investigadores, cientistas, mas também artistas e profissionais de diversas competências encontram nas cidades as possibilidades de intercâmbios de conhecimento e de transferência tecnológica informal, assim como a possibilidade de expressar a sua potencialidade em termos de inovação (Vico, 2016).

Portanto, as cidades ao nível global, competem mais do que nunca, com o objetivo de sediar um grande evento como uma Olimpíada. As suas transformações e as possibilidades de desenvolvimento que se obtêm acolhendo os megaeventos encontram um interesse maior. Assim como afirma Guala (2002b), a diversificação de iniciativas de alto nível, esportivas, culturais e artísticas, é muito elevada; a terceirização crescente da economia e o fim da cidade fordista relançam a competição internacional das cidades. É neste quadro competitivo que muitas cidades concorrem para poder obter a possibilidade de sediar uma Olimpíada. 
A organização de um grande evento como uma Olimpíada comporta consideráveis investimentos que devem ser realizados para responder às exigências do Comitê Olímpico Internacional e, na atual conjuntura global, os territórios, numa perspectiva de competição internacional, são sempre mais chamados a elevar os próprios sistemas estruturais e infraestruturais. É neste cenário que as Olimpíadas deveriam desenvolver um importante papel como catalisadores de transformações territoriais e sociais, mudanças que às vezes não acontecem ou impactam de maneira negativa a população local e o território. Conforme afirma Gilmar Mascarenhas:

\begin{abstract}
Operações urbanas emblemáticas que vêm, quase sempre, acompanhadas das parcerias público-privadas, da desregulamentação edilícia, da concessão de vantagens fiscais e da privatização dos espaços urbanos, com escassos canais de diálogo democrático, gerando, por conseguinte, um quadro de tensões e um amplo leque de estratégias de ativismo social. Sem dúvida, tais elementos vêm se repetindo a cada edição dos Jogos, ainda que variando segundo a particularidade de cada cidade e de cada conjuntura (Mascarenhas, 2016, p. 06).
\end{abstract}

Infelizmente esses aspectos se repetem de quatro em quatro anos a cada edição das Olimpíadas com características diferentes dependendo de cada cidade-sede e do contexto político, econômico e social do momento.

Nas últimas três décadas, na nossa sociedade influenciada sempre mais pelo fenômeno da globalização, as Olimpíadas, assim como outros importantes megaeventos, tornaram-se um verdadeiro negócio econômico global. A competição entre cidades para angariar o direito de acolher uma Olimpíada é determinada principalmente por lógicas de mercado dominando as teorias e práticas do planejamento do território (Oliveira, 2013).

Os Jogos Olímpicos de fato constituem instrumentos para atrair fluxos de capitais internacionais, acumulação local e reorganização de circuitos de circulação. Atrás da justificativa do aumento do prestígio e da visibilidade internacional e da regeneração urbana da cidade, se escondem muitos outros interesses por trás como o interesse pelo poder, o interesse pelo capital político para exercer influência local e um processo de acumulação econômica de recursos.

Este processo de acumulação configura-se como um verdadeiro negócio globalizado, um mecanismo standard de acumulação relacionado com a política econômica global que repete-sepelas cidades que acolheram as Olimpíadas como Seul, Pequim, Atena, Londres e por último, Rio de Janeiro. Conforme Gaffney:

Para estimular a acumulação de poder e de dinheiro, é necessário estimular a geração de novos fluxos para uma cidade ou local. Quer dizer, colocar no mapa global uma cidade é fazer com que os fluxos internacionais financeiros conheçam 
aquela cidade, entendam seu funcionamento e saibam que terão portas abertas para negócios. Esse processo atrai investimentos e mais fluxo de dinheiro para determinado local - turismo, eventos, negócios e empresas, e por aí vai. (...) Esse sinal tem várias direções, é um marco para os fluxos financeiros internacionais, como também para os capitais regionais e locais interessados em participar do negócio (Gaffney, 2016, p. 01).

Sucessivamente, depois da escolha da cidade como anfitriã dos jogos, acontece um incremento dos fluxos financeiros com diferentes atores atraídos para efetuar mais negócios. Mas, assim como salienta Gaffney (2016), para que esses fluxos financeiros tornarem-se acumulação e, consequentemente, poder, é preciso inserir esses fluxos num circuito de circulação, como por exemplo, em investimentos em obras de infraestrutura, de transporte e de mobilidade urbana, estádios, instalações esportivas, imóveis, centros para a mídia etc.

\section{OS RECENTES MEGAEVENTOS ESPORTIVOS NO BRASIL}

O Brasil pela sua fase atual e pelo momento de crescimento naturalmente já tem uma procura pelos investimentos em infraestruturas muito grande em diversos setores. Na verdade o Mundial de Futebol de 2014 e as Olimpíadas de 2016 são fatos políticos e eventos importantes que foram catalisadores e motivadores destes investimentos. Mas os megaeventos esportivos organizados para o país (Taça das Confederações de 2013, Mundial de Futebol de 2014 e Jogos Olímpicos e Paraolímpicos de 2016) são considerados, acima de tudo, um instrumento de propaganda governamental, com a intenção de promover o patriotismo e criar certo consenso político e social.

Os megaeventos no Brasil geraram uma série de impactos políticos, econômicos e sociais nas diferentes cidades do país. As obras necessárias de adequação da estrutura urbana para acolher o megaevento criaram um novo ciclo de acumulação urbana ao liberar setores das cidades para novos negócios imobiliários. Ao mesmo tempo, afetaram às populações locais nos seus territórios, as quais sofreram com destruições e remoções forçadas para permitir a implantação de novas infraestruturas. O conflito mais grave, portanto, aconteceu em torno das remoções forçadas da população de favelas e comunidades por causa das obras do Mundial de Futebol e das Olimpíadas, praticamente em todas as cidades-sede. Milhares de pessoas foram retiradas de seus lares de forma compulsória, muitas delas sem amparo legal algum (Rayes \& Chahine, 2014).

Diversas instituições, investigadores, redes sociais e movimentos (como os Comités Populares da $\mathrm{Copa}^{\mathrm{l}}$ ) têm denunciado veementemente esta prática, que expõe o grau de

\footnotetext{
${ }^{1}$ No Brasil é mais utilizada a expressão "Copa” mas nos outros países lusófonos utiliza-se a palavra "Mundial”
} 
desigualdade social e vulnerabilidade das populações mais pobres que caráteriza o Brasil, tanto perante o mercado quanto perante o estado. Como afirma também o Dossiê da Articulação Nacional dos Comitês Populares da Copa (2011, p. 83):

\begin{abstract}
Estes megaeventos têm gerado efeitos negativos sobre diversos segmentos sociais, especialmente sobre aqueles que historicamente são excluídos/as, como: moradores/as de assentamentos informais, migrantes, moradores em situação de rua, trabalhadores/as sexuais, mulheres, crianças e adolescentes, comunidades indígenas e afrodescendentes, vendedores/as ambulantes e outros trabalhadores/as informais, inclusive da construção civil. As remoções e os despejos forçados desses grupos sociais são as violações mais comuns no Brasil e em outros países sede de megaeventos. Seus efeitos perversos são particularmente ampliados através da imposição do Poder Público e dos Comités promotores dos eventos, de um verdadeiro 'estado de exceção', instituído especialmente no contexto dos jogos, que permite a flexibilidade das leis e suspensão de direitos antes e durante os jogos, ameaçando, assim, os mecanismos de defesa, proteção social, garantia e promoção de Direitos Humanos.
\end{abstract}

Os gastos públicos nas obras de infraestrutura, além dos estádios de futebol (dos quais nove foram estaduais e somente três privados), foram duramente criticados, já que os investimentos podiam ter tido um destino social que gerasse benefícios para a maioria da população. Com esta infinidade de questões, a academia brasileira está envolvida na discussão e investigação destes temas. Um grande número de projetos de investigação, pesquisas e seminários estão a discutir os impactos do Mundial de Futebol e das Olimpíadas na sociedade e nas cidades brasileiras assim como o presente estudo. O Brasil não é um país com tradição no acolhimento e promoção de megaeventos esportivos. Apenas havia recebido um Mundial de Futebol em 1950, os Jogos Pan-americanos de 1967 e 2007 (estes últimos de maior expressão na América Latina) e competições esportivas de menor importância como as Copa América de Futebol e a Formula 1, este último como o evento mais expressivo e realizado ininterruptamente desde 1972 no circuito de Interlagos na cidade de São Paulo.

\title{
5. CASO DE ESTUDO - OS JOGOS OLÍMPICOS DO RIO DE JANEIRO DE 2016
}

\subsection{Rio de Janeiro, uma cidade à venda}

As Olimpíadas do Rio de Janeiro, de 2016, configuram-se como mais uma etapa desse modelo de negócio e de uso hierárquico e corporativo do território, constituído pela coalizão de diferentes interesses de vários atores e fatores envolvidos como, in primis, as autoridades políticas, a elite econômica local e os fluxos financeiros internacionais. A eleição da cidade carioca como sede dos jogos “sintetiza a expressão do 'consenso' entre os grupos hegemônicos no país em torno do objetivo de inserir a cidade no circuito mundial de produção do espetáculo esportivo" (Oliveira, 2013, p. 10). 
"O Rio torna-se, ao mesmo tempo, centro de dominação política, atratividade e mobilidade de capitais e pessoas/turistas/espectadores e palco por excelência da megavalorização dos capitais associados à rede olímpica” (Egler, 2017, p. 04).

Assim como afirma o professor Sousa e Silva Filho (2016), desde quando Rio de Janeiro foi escolhida como sede dos Jogos Olímpicos em 2009, a cidade carioca tornou-se palco de um experimento de uma gestão repressiva dos direitos sociais com a intenção de criar uma imagem mais agradável para os grandes grupos corporativos e o capital econômico internacional, em conflito com a sociedade do Rio de Janeiro.

Ainda de acordo com os autores supracitados, as grandes empresas, junto com as autoridades políticas em todos os níveis (federal, estadual e municipal) e o COI, quiseram transformar o Rio de Janeiro em mercadoria, uma cidade à venda, seu espaço, seu território está à venda ou pode ser alugado e, consequentemente, a população local também está à venda e faz parte desse processo. A cidade carioca tem sido reorganizada geograficamente para acolher os megaeventos com o pretexto de uma maior visibilidade, melhoramento da imagem e maior visibilidade a nível internacional e atração de novos investimentos e negócios.

Porém, estes interesses que pretendem transformar a "cidade olímpica" numa cidadeempresa, se chocam com a reação da população local que, através de numerosas manifestações e protestos antes, durante e depois da realização da Copa do Mundo de 2014 e dos Jogos Olímpicos de 2016 considera que o Rio de Janeiro tem outros problemas e outras prioridades como o melhoramento do sistema de saúde e de educação, do saneamento básico, da moradia e da segurança.

De acordo com Gaffney (2016), a herança que os Jogos Olímpicos do Rio 2016 deixaram para o território e para a sociedade carioca é de endividamento do Estado e da Cidade, expropriações e remoções de mais de 77 mil residentes (sobretudo na Vila Autódromo e na zona portuária) associadas ao fenômeno da gentrification e do enobrecimento de algumas áreas com a forte especulação imobiliária, assim como outros casos de violações de direitos humanos, falência do sistema de saúde, educação e segurança com uma polícia mais militarizada e menos treinada no âmbito da operação das Unidades de Polícias Pacificadoras (UPP). O projeto urbano de revitalização da cidade carioca encentrou-se em três aspectos principais:

- Fortalecimento da centralidade já existente, concentrando as intervenções na Zona Sul onde mora a maior parte da elite econômica da cidade; 
- A reestruturação da centralidade decadente, fixando como objetivo o recuperação da área portuária no centro da cidade;

- A criação de uma nova centralidade, situada na Barra da Tijuca, através de vultosos investimentos nessa região.

Esse projeto de reestruturação urbana em áreas consideradas nobres promove a mercantilização do espaço urbano que incrementa os processos de segregação e guetização sócio-territoriais com o mecanismo da espoliação urbana e relocalização dos mais pobres e marginais na cidade através das expropriações e remoções.

A política urbana do projeto olímpico baseia-se na valorização imobiliária e inclui também obras de transporte e mobilidade urbana, instalações esportivas e UPP nas zonas de expansão do capital imobiliário como principalmente em Barra da Tijuca, Jacarepaguá, Centro, "Porto Maravilha" e Maracanã, além também das regiões já valorizadas e de interesse turístico e de residência das elites como Copacabana, Ipanema e Leblon, entre outras. As obras concernem diversas áreas ocupadas por populações de baixa renda, marginalizadas e desprezadas pelo setor imobiliário e abandonadas pelas autoridades que, de repente, tornaramse interessantes pela especulação mobiliaria, considerando, especialmente, os investimentos olímpicos.

Para traçar o circuito reservado para os Veículos Leves sobre Trilhos (VLT), para criar as faixas rápidas somente para a circulação dos ônibus, para construir ou transferir para outro lugar as instalações esportivas, foi preciso, portanto, deslocar a população e demolir áreas de alguns bairros. A Zona Oeste do Rio foi, com certeza, a área mais afetada com mais de 3.500 edifícios expropriados (Fontaine, 2016).

Em particular, a Vila Autódromo, onde moravam mais de 700 famílias desde 1970 e onde foi realizado o Parque Olímpico, é considerada o emblema dessas remoções e expropriações. Antônio Franklin (Fontaine, 2016, p. 26), presidente da associação dos moradores do bairro, afirma que as autoridades nunca avisaram às famílias que tinham que deslocar-se e muitos residentes descobriram a notícia pela mídia.

Rolnik (2015), professora de arquitetura da Universidade de São Paulo (USP) e Relatora do Conselho de Direitos Humanos da Organização das Nações Unidas (ONU) para o Direito à Moradia Adequada, confirma que ocorreu expulsões forçadas e violações manifestas dos direitos humanos e das leis internacionais no processo de expropriação ligado às obras para a Copa do Mundo de 2014 e às Olimpíadas de 2016. Em particular, aconteceram intimidações obrigando a sair também os que ficavam e resistiam a defesa da própria 
habitação. Além disso, o valor das indenizações propostas resultou ser muito inferior ao preço de mercado dos imóveis. Mas o aspecto mais grave consiste na quase total ausência de transparência e de diálogo entre as autoridades e a sociedade civil (Rolnik, 2015; Fontaine, 2016).

A seguir, apresentam-se alguns dados sobre quanto foi gasto nos Jogos Olímpicos do Rio de Janeiro de 2016 e de onde deriva este dinheiro. Para perceber melhor, é preciso repartir o orçamento total em três partes: Orçamento do COI; Matriz de responsabilidades; Plano de Políticas Públicas.

O primeiro ponto trata-se do orçamento do comité organizador local, instituição privada, responsável pelos custos operacionais do megaevento e das competições. São gastos como: refeições dos atletas, uniformes, hospedagem, transporte das equipes e material esportivo no geral. Este orçamento corresponde a 7,4 bilhões de reais e é $100 \%$ coberto por patrocínio e outras fontes de receita da iniciativa privada sem nenhuma verba pública (Ministério do Esporte, 2016).

Pelo que concerne à "Matriz de responsabilidades", trata-se de uma verba destinada exclusivamente a projetos associados à realização dos jogos como as instalações olímpicas que não aconteceriam caso o Rio não fosse escolhido para acolher o megaevento. Entre estes projetos figura o Parque Olímpico. O valor desse orçamento foi de 6,67 bilhões de reais sendo que 4,2 bilhões vem da iniciativa privada (Ministério do Esporte, 2016).

Destaca-se, ainda, o Plano de Políticas Públicas, o qual representa o tão discutido "legado" dos Jogos Olímpicos ou investimentos em políticas públicas. Esse plano propos a realização de 27 projetos que possuem baixa ou nenhuma relação direta com os Jogos Olímpicos, mas que se beneficiam do megaevento para antecipar ou ampliar investimentos a nível federal, estadual e municipal, em infraestruturas e políticas públicas (Ministério do Esporte, 2016).

Entre estes projetos, ressaltam-se alguns mais importantes, tais como: os BRTs, o Porto Maravilha, o VLT do Centro, as Piscinas da Praça da Bandeira, a Linha 4 do Metrô, os Laboratórios de Controle de Doping. Dos 24,6 bilhões de reais do legado, aproximadamente 10,3 bilhões de reais, ou seja, o $43 \%$, deriva da iniciativa privada e o restante $57 \%$ provem de parcerias entre empresas / consórcios públicos e privados (PPP) ou exclusivamente de recursos públicos (Ministério do Esporte, 2016). 
Gráfico 1 - Investimentos no Rio de Janeiro para os Jogos Olímpicos de 2016

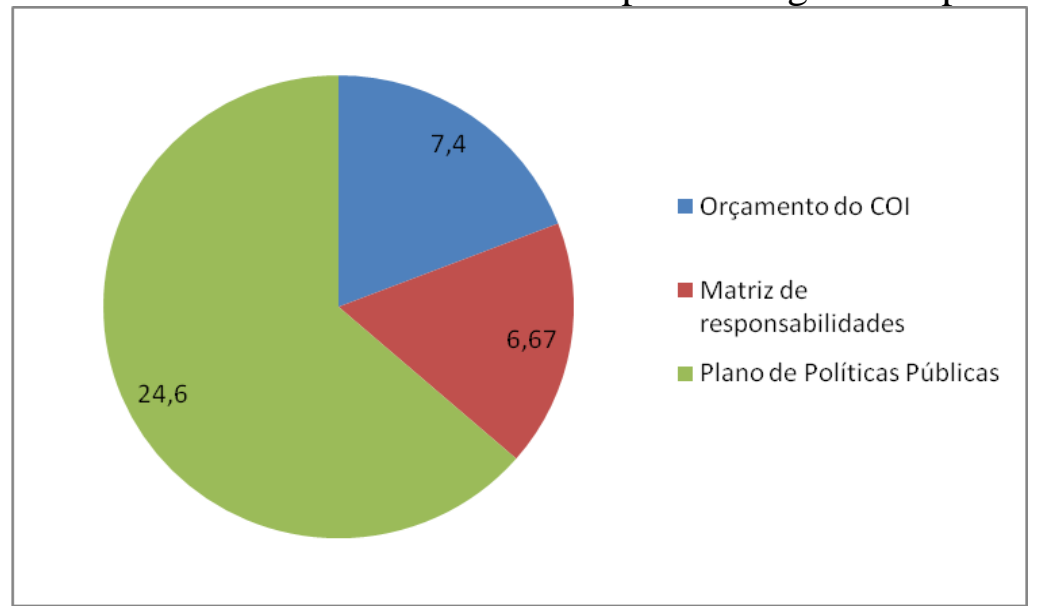

Fonte: Ministério do Esporte, 2016.

Sobre a gestão atual e futura das instalações e das infraestruturas esportivas, é preciso lembrar de que o custo de manutenção das instalações é muito elevado. E hoje em dia parte dessas estruturas foi privatizada e outra parte foi entregue ao Ministério do Esporte.

De fato, depois da grande festa olímpica, tinha-se a impressão que o Brasil ia ter uma geração esportiva de atletas com lugares apropriados para treinar como, por exemplo, as piscinas olímpicas e as arenas de ginástica, mas, muitas estruturas foram entregue para o exército, a marina e a aeronáutica e os atletas deviam e devem ser contratados para usar as instalações esportivas, assim como aconteceu pela piscina olímpica que foi entregue para o exército. A maioria das estruturas, portanto, não permaneceram como legado para o esporte.

Sendo assim, houve uma falta de planejamento relativo aos recursos utilizados para os investimentos realizados com relação às estruturas, principalmente, esportivas e ao seu uso posterior ao megaevento. Isso já aconteceu para a Copa do Mundo de 2014 com alguns estádios que viraram "elefantes brancos" e estão sendo poucos aproveitados e que possuem elevados custos de manutenção (é o caso de Brasília, Cuiabá, Manaus e Natal) e está acontecendo agora depois das Olimpíadas com as instalações olímpicas.

Nesse contexto, relativamente às obras imobiliárias da Vila Olímpica, no Rio de Janeiro, apenas $7 \%$ dos apartamentos foram vendidos e o restante está abandonado, de fato essas habitações foram avaliadas com preços muito elevados.

Desta forma, se constitui mais um recurso que poderia ser aproveitado de outra forma, abrigando, por exemplo, pessoas de baixa renda como aconteceu para a Vila Olímpica de Londres que, antes era um espaço degradado e periférico, mas que, graças a um projeto social de habitação, tornou-se um lugar de moradia das pessoas de baixa renda e onde $50 \%$ dos residentes possuem até subsídios para o pagamento dos alugueis. 
Comparar valores dos diferentes Jogos Olímpicos é difícil já que a realidade de cada cidade é diferente. Mesmo assim, podemos ter uma noção de grandeza com alguns números. Em 2008, Pequim gastou 65 bilhões de reais na realização do evento. Já em 2012, o governo inglês investiu 33 bilhões de reais que, somados aos 8,2 bilhões de reais do Comité Olímpico, resultaram em 41,2 bilhões de reais (Ministério do Esporte, 2016).

Segundo o Ministério do Esporte (2016), dos 38,67 bilhões de reais gastos nos Jogos Olímpicos do Rio de Janeiro, $57 \%$ veio da iniciativa privada e $43 \%$ foi investimento o Governo Federal e Estadual e dos cofres públicos. O uso de verba pública para a realização de grandes obras, muitas das vezes reputadas desnecessárias, tem gerado um mal-estar geral da população local que, através de protestos e manifestações, mas também em debates e discussões públicas, sublinhava como estes recursos poderiam ser investidos para realizar investimentos em outros setores prioritários para o Rio de Janeiro. Outros graves problemas relacionados com a utilização de recursos públicos são o endividamento do Estado e uma difusão da corrupção com desvios de verba pública.

Entretanto, o turismo sobressai por despertar diversificados segmentos de eventos que se realizam de forma genérica, onde, de acordo com os interesses programados tende a proporcionar fluxo de visitantes, a rentabilidade por meio da ocupação da rede hoteleira, do setor imobiliário, do usufruto dos meios de transporte, do setor de entretenimento, assim como de diversos serviços de apoio aos turistas, que independentemente da motivação de viagem do turista, fazem parte dos elementos que se incluem nas suas despesas.

Tabela 3 - Dados do Turismo durante os jogos Olímpicos

\begin{tabular}{|l|l|}
\hline Turismo & Dados \\
\hline Total de turistas & 1,2 Milhões \\
\hline Turistas estrangeiros & 410 Mil (EUA, Alemanhã, Argentina) \\
\hline Proveniência de turistas brasileiros & $43 \%$ São Paulo, 9\% Gaúchos e 7\% Mineiros \\
\hline Taxa de ocupação hoteleira & $94 \%$ \\
\hline Média de gastos de turistas estrangeiros na cidade & 424 Reais por dia \\
\hline Média de gastos de turistas brasileiros na cidade & 310 Reais por dia \\
\hline
\end{tabular}

Fonte: Ministério do Turismo, 2016.

O mercado de eventos é fundamental para o turismo, que se chega a estabelecer uma relação sinérgica. O turismo de eventos é considerado um segmento que estimula o esforço de diversos setores, assim como lida com múltiplos eventos, a exemplo da área cultural, econômica, esportiva, entre outras, (Britto \& Fontes, 2002). Trata-se de eventos que servem de atrativos aos destinos turísticos em que as motivações dos turistas são variadas. 
Em 2016, o número de turistas foi estimado em 6.546.770 e em 2017 a tendência foi de aumento para 6.588.770 turistas (Agência Brasil, 2018). Uma diferença de 42 mil turistas que pode ter sido fomentada pela imagem premediada do destino turístico. Mas também, a média por ano do número do turista em 2017 estabelecida foi de 54.9058, enquanto que em 2016, durante a realização das olimpiadas, Rio de Janeiro acolheu 1,2 milhões de turistas que superou a estimativa média mensal do ano 2017.

Contudo, de forma global os dados de 2017 superam os de 2016, mas estes dados nos levam a refletir que a concentração de turistas num determinado momento com fins específicos nas circunstâncias dos megaeventos, nem sempre o volume de pessoas e dos seus gastos representa vantagens ao território.

\subsection{Exigências do COI e endividamento do Rio de Janeiro}

Uma das críticas em relação ao COI está relacionada com as especificações e exigências que o COI impõe aos países e às cidades para a preparação de uma Olimpíada como verdadeiras regras e frequentemente as cidades não conseguem atender estas demandas tão elevadas. Muitas vezes não compensa se quem recebe um megaevento é um país subdesenvolvido ou emergente que não possui uma base de infraestruturas e instalações esportivas concretas para a realização de um megaevento dessas dimensões.

Um exemplo emblemático concerne às estruturas olímpicas do Rio de Janeiro e, em particular, o Velódromo, onde as madeiras para a construção da pista, vieram da Sibéria e, tratando-se de madeira que provem de um lugar muito frio, elas precisam ser mantidas constantemente à uma temperatura de 26 graus com um custo de 18 mil reais a cada seis horas ou seja dois milhões mensais, e tudo isso somente para pagar os custos de energia elétrica de uma arena só (Redação Novo Tempo, 2017).

Devido às elevadas exigências e regras que o COI impõe para as cidades anfitriãs, para as próximas Olimpíadas de 2024 somente duas cidades se candidataram: Paris e Los Angeles. De fato, Roma, Bucareste e Hamburgo, depois de perceber o endividamento que muitas cidades tiveram depois das Olimpíadas e a falta de um verdadeiro legado duradouro como para o caso de Atenas 2004 e atualmente de Rio de Janeiro 2016, retiraram a própria candidatura.

Isso porque houve uma grande pressão por parte das populações locais que não queriam que a própria cidade se candidatasse, considerando que os gastos com a organização dos Jogos Olímpicos não valia a pena e que o retorno em termos de legados não ia ser relevante no futuro. 
Consequentemente, o COI decidiu conceder pela primeira vez na história dos Jogos Olímpicos da era moderna, a organização das Olimpíadas de 2024 para Paris e às de 2028 para Los Angeles, sem praticamente a presença de uma competição para a candidatura entre as cidades, afirmando também que para o futuro iriam mudar as regras de candidatura para evitar que não aparecesse nenhuma cidade em querer organizar os jogos.

Desde 2016, o Estado do Rio de Janeiro consta entre os estados mais endividados do Brasil, é um dos estados que mais deve para a União e que tem atrasado o pagamento dos salários com frequência.

Além disso, ocorreram cortes de gastos em muitos setores públicos como principalmente na área da saúde e da educação, além do aumento do custo de transporte para a população, o fechamento de restaurantes e farmácias populares. Boa parte dessa crise está relacionada também com a organização dos Jogos Olímpicos, o que elevou o gasto público com a manutenção das instalaçoes olímpicas.

De fato, de acordo com o Tribunal de Contas do Estado do Rio de Janeiro (TCE-RJ) (Agência Brasil, 2017), o empréstimo para custear as despesas com os Jogos Olímpicos de 2016 incrementou o endividamento do estado e, atualmente, a dívida pública estadual consolida-se em 106,15 bilhões de reais. O TCE-RJ adverte também que a obtenção de empréstimos para sanar as contas públicas pode piorar definitivamente a situação fiscal daquele estado.

Conforme as informações reportadas pela Agência Brasil (2017), de acordo com o relatório do TCE-RJ, a grave situação de endividamento do Estado do Rio de Janeiro começou logo depois que o Rio foi escolhido como sede das Olimpíadas em 2009, com autorizações para contratação de volumes elevadíssimos em operações de crédito. No período compreendido entre 2012 e 2015, foram 22,39 bilhões de reais em empréstimos para o Estado do Rio de Janeiro. Deste valor, o 78,6\% foi utilizado para custear os gastos ligados às Olimpíadas e Paraolimpíadas de 2016.

O grande problema da corrupção fez que todas as obras que foram comissionadas e realizadas (mas algumas nem saíram do papel) tiveram um custo enorme, muito superior ao custo que inicialmente foi orçamentado ou ao custo verdadeiro para a realização das obras.

Todo o dinheiro investido, além do fato de não converter-se em legado, provocou um corte no que concerne os serviços públicos. De fato o Estado do Rio de Janeiro entrou definitivamente em crise econômica logo antes do início das Olimpíadas, e isso não foi por acaso. Portanto, todos esses gastos desnecessários e essa elevada corrupção se traduziram em pobreza. 
Conforme Orlando Alves dos Santos Júnior ${ }^{2}$, professor da UERJ e membro do Observatório das Metrópoles (2019), o dinheiro foi totalmente desperdiçado. Baste pensar no Aeroporto Internacional Galeão do Rio de Janeiro, com a criação de um novo terminal que nunca foi utilizado, porque já era suficiente o outro anterior; o estádio do Maracanã que já tinha sido reformado antes da Copa e que teve uma outra reforma (mas que segundo a opinião de todo o mundo era melhor como era antes) somente para as Olimpíadas e somente para gastar mais dinheiro; a linha 4 do metrô onde foram feitas poucas paradas que situam-se no "meio do nada", para um trajeto muito longo, e onde no final começa outro meio de transporte, o BRT, que é vendido como um grande projeto de mobilidade urbana e que não é outra coisa do que uma língua de asfalto com um pequeno muro utilizável para o transito desses ônibus, uma faixa prioritária, trata-se portanto simplesmente de uma linha de ônibus, e que custou bilhões de reais, tudo isso somente para conectar a estação de Jardim Oceânico ao Parque Olímpico, e com problemas de infraestruturas para os que têm problemas de mobilidade e deficiência física.

\subsection{Esquemas de corrupção}

Boa parte dos gastos que saiu dos cofres públicos foi para abastecer esquemas de corrupção. Segundo dados da Organização das Nações Unidas (ONU) o custo da corrupção no Brasil é de 200 bilhões de reais por ano (Terra - Istoé, 2016). O procurador federal Paulo Roberto Galvão também ressaltou que somente para o caso da Petrobras, no âmbito da operação Lava Jato, descobriu-se que houve desvio ilegal de fundos do valor compreendido entre 30 bilhões de reais e 40 bilhões de reais (Terra - Istoé, 2016).

No centro do maior escândalo de corrupção do Brasil revelado pela operação Lava Jato consta a construtora Odebrecht, uma das mais importantes empreiteiras do Brasil e responsável pela construção de muitas obras de infraestruturas, imobiliárias e instalações esportivas para a Copa do Mundo de Futebol de 2014 e os Jogos Olímpicos do Rio de Janeiro. Recentemente, Carlos Arthur Nuzman que era o presidente do Comitê Olímpico do Brasil (COB) desde 1995, foi preso pela Polícia Federal brasileira porque foi considerado protagonista de um esquema criminoso que juntou os interesses econômicos de políticos e empresários cariocas com os dos membros do Comitê Olímpico Internacional (COI) os quais,

\footnotetext{
${ }^{2}$ Entrevista não confidencial realizada em 20 de Fevereiro de 2019.
} 
descobriu-se, eram dispostos a vender seus votos para a escolha do Rio de Janeiro como anfitriã dos Jogos Olímpicos de 2016 (Comitê Olímpico Brasileiro, 2017).

A vitória brasileira para sediar os Jogos Olímpicos foi, portanto, uma farsa e até hoje existe a suspeita que cidades como Madrid e Tóquio, que apresentaram também a própria candidatura, teriam obtido mais votos que o Rio de Janeiro.

Outra personalidade célebre que também ficou envolvida em um escândalo de corrupção foi o ex-ministro do turismo Henrique Eduardo Alves. Ele foi preso pela Polícia Federal em um desdobramento da operação Lava Jato que investigava corrupção ativa e passiva e lavagem de dinheiro na construção da Arena das Dunas, em Natal-RN, (G1 Globo, 2017) durante a Copa do Mundo de Futebol de 2014, estádio que substituía ao antigo estádio "Machadão".

Depois da Copa do Mundo de 2014, também a FIFA está a passar pelo pior momento da sua história. Executivos da FIFA foram presos e muitos outros estão sendo investigados por episódios de corrupção relativos a vários aspetos e a diferentes Campeonatos do Mundo de Futebol, entre estes está o Mundial do Brasil de 2014 e os próximos Mundiais da Rússia 2018 e do Qatar de 2022 (Vico, 2016).

\section{CONSIDERAÇÕES FINAIS}

Depois da análise realizada, é evidente que no âmbito do planejamento e da organização de futuros megaeventos, ocorre seguramente mais transparência na gestão do mesmo, já desde as primeiras fases de concepção da proposta de querer organizar o megaevento, passando pela apresentação da candidatura, ao planejamento do evento e à realização do mesmo até chegar ao pós-evento (Vico, 2016; Vico, Uvinha \& Gustavo 2018).

Particularmente importante é a fase do pós-evento que consiste na avaliação técnica, administrativa e dos participantes, examinando ou verificando se o evento foi bem-sucedido e se foram atingidos os objetivos inicialmente estabelecidos. Além disso, faz-se a confrontação dos resultados esperados com os obtidos, possibilitando identificar os pontos positivos e negativos do evento e realizar, assim, ações corretivas prevenindo futuras repetições. Porém, trata-se de uma fase que é frequentemente esquecida ou deixada de lado pelos organizadores (Allen et al., 2003; Matias, 2004; Pedro et al., 2005).

Além disso, é preciso um envolvimento dos moradores desde as primeiras fases do planejamento mediante: uma gestão mais cuidadosa dos interesses dos moradores; uma maior valorização das tradições e dos elementos da cultura local e um clima de decisão mais participativo. 
Numa realidade onde é preeminente o aspeto mercadológico e onde a atividade esportiva se junta com a iniciativa econômica, tanto privada como pública, realizar e perseguir ao melhor o objetivo econômico não deve deixar em segundo plano as virtudes da atividade esportiva e o aspeto ético e moral. Não há dúvidas acerca da criação de valor adicional por parte de um megaevento como uma Olimpíada, tanto a nível local como nacional. Mas este valor adicional seguramente deve incluir um envolvimento da população local. Portanto todos os efeitos negativos analisados ao longo do trabalho poderiam ser afastados através da colaboração entre organizadores, patrocinadores e empresas com as entidades locais, através de um maior envolvimento dos residentes e com uma transparência total em todas as ações.

\section{REFERÊNCIAS}

Agência Brasil. (2017). Empréstimo para custear Rio 2016 aumentou endividamento do estado, diz TCE-RJ. Recuperado em 05, janeiro, 2018, de http://agenciabrasil.ebc.com.br/geral/noticia/2017-02/emprestimo-para-custear-rio-2016aumentou-endividamento-do-estado-diz-tce-rj

Agência Brasil. (2018). Número de turistas estrangeiros bate record em 2017. Recuperado em 08, fevereiro, 2018, de http://agenciabrasil.ebc.com.br/economia/noticia/2018-03/numerode-turistas-estrangeiros-no-pais-bate-recorde-em-2017-e-chega-65

Allen, J., O’Toole, W., McDonnel, \& I., Haris, R. (2003). Organização e Gestão de Eventos. Rio de Janeiro: Elsevier.

Brasil perde cerca de $R \$ 200$ bilhões por ano com corrupção, diz MPF. (2016). Terra - Istoé. Recuperado em 07, janeiro, 2018, de https://istoe.com.br/brasil-perde-cerca-de-r-200-bilhoespor-ano-com-corrupcao-diz-mpf/.

Britto, J., \& Fontes, N. (2002). Estratégias para eventos: uma ótica do marketing do turismo. São Paulo: Aleph.

Chalkley, B., \& Essex, B. (1998). Olympic Games: catalyst of urban change. Leisure Studies, 17, 187-206.

Chalkley, B., \& Essex, S. (1999). Urban development through hosting international events: a history of the Olympic Games. Planning Perspectives, 14(4), 369-394.

Comitê Olímpico Brasileiro. (2018). Comitê Olímpico Brasileiro: Polícia Federal prende Nuzman, presidente do Comitê Olímpico Brasileiro. El País. Recuperado em 03, janeiro, 2018, de https://brasil.elpais.com/brasil/2017/10/05/politica/1507202626_211045.html.

Dossiê da Articulação Nacional dos Comitês Populares da Copa (2011). Megaeventos e Violações de Direitos Humanos no Brasil. Rio de Janeiro: CEDECA.

Egler, T. (2017). A rede olímpica no jogo do Rio. Sessão temática 10: Perspectivas para o planejamento urbano e regional. Anais do XVII Encontro Nacional da Associação Nacional 
de Pós-Graduação e Pesquisa em Planejamento Urbano e Regional - Enanpur, São Paulo, SP, Brasil,

Ex ministro Henrique Eduardo Alves é preso em operação da PF. (2017). G1.globo.com. Recuperado em 03, março, 2018, de https://g1.globo.com/rn/rio-grande-do-norte/noticia/exministro-henrique-eduardo-alves-e-alvo-de-mandado-de-prisao.ghtmlFontaine, J. J. (2016). Rio de Janeiro et les Jeux Olympiques : Une cité réinventée. Paris: L'Harmattan.

Gaffney, C. (2016). Olimpíada Rio 2016: para o benefício de quem? Entrevista para o Instituto Nacional de Ciência e Tecnologia - INCT - Observatório das metrópoles.

Recuperado em 07, janeiro, 2018, de http://observatoriodasmetropoles.net/index.php?option=com_k2\&view=item\&id=1646\%3Aol imp\%C3\%ADada-rio-2016-para-o-benef\%C3\%ADcio-de-quem\%3F\&Itemid=171\#.

Guala, C. (2002b). Per una tipologia dei mega-eventi. In: Dansero, E. \& Segre, A. Bollettino della Società Geografica Italiana, VII, pp. 743-755.

Hall, C. M. (1997). Mega-Events and Their Legacies. In Murphy, P. E. Quality Management in Urban Tourism, pp. 75-87.

Mascarenhas, G. (2016). Apresentação. Dossiê: Cidades Olímpicas. Revista Advir, (35).

Matias, M. (2004). Organização de Eventos: Procedimentos e Técnicas. (3a. ed.). Barueri SP: Manole.

Ministério do Esporte (2016). Gestão do legado e Megaeventos. Recuperado em 02, janeiro, 2018, de www.brasil2016.gov.br.

Oliveira, N. (2013). A produção da cidade através do espetáculo esportivo: quando a exceção se torna regra. E-Metropolis - Revista eletrônica de estudos urbanos e regionais, (13).

Pedro, F., Caetano, K., Christiani, \& Rasquilha L. (2005). Gestão de Eventos. Lisboa: Quimera.

Rayes, C., \& Chanine, M. (2014). Les exclus du Mondial. Libération, 2-5.

Redação Novo Tempo (2017). Recuperado de http://novotempo.com/redacaont/ Ritchie, J. (1984). Assessing the Impact of Hallmark Events: Conceptual and Research Issues. Journal of Travel Research, 23 (1), 2-11.

Rolnik, R. (2015). Guerra dos Lugares: A colonização da terra e da moradia na era das finanças. São Paulo: Editora Boitempo.

Sousa, D., \& Silva Filho, D. (2016). Prefazione in Spera, L. Crimine e favelas - Traffico di droga, violenza istituzionale e politiche di pubblica sicurezza a Rio de Janeiro dalla fondazione alla pacificazione per le Olimpiadi 2016. Edizioni Eiffel: Ogliastro Cilento (Sa).

Vico, R. P. (2016). Os megaeventos desportivos na percepção da comunidade local: o caso do Mundial de Futebol do Brasil de 2014 pelos moradores de Itaquera em São Paulo. Dissertação Mestrado em Turismo e Gestão Estratégica de Destinos Turísticos, Escola Superior de Hotelaria e Turismo do Estoril, Portugal. 
Vico, R. P., Uvinha, R., \& Gustavo, N. (2018). Sports mega-events in the perception of the local community: the case of Itaquera region in São Paulo at the 2014 FIFA World Cup Brazil. Soccer \& Society, 19(2).

Watt, D. C. (2004). Gestão de eventos em Lazer e Turismo. Porto Alegre: Bookman.

Whitson, D., \& Horne, J. (2006). Underestimated costs and overestimated benefits?

Comparing the outcomes of sports mega-events in Canada and Japan. Sociological Review, 54(2), 71-89.

\section{FORMATO PARA CITAÇÃO DESTE ARTIGO}

VICO. R. P. \& CHIUNDILA, V. C. (2019). Turismo e o pós-evento olímpico: uma gestão mercadológica da cidade do Rio de Janeiro. Revista de Turismo Contemporâneo, 7, Edição Especial, 3-27. https://doi.org/10.21680/2357-8211.2019v7n0ID16978 